\title{
Gestational Diabetes: A Conundrum for Mother, Baby and Physician
}

\section{James A Bofill and John C Morrison*}

Departments of Obstetrics and Gynecology; University of Mississippi Medical Center, Jackson, Mississippi, USA

There are nearly 4 million births in the United States each year and in approximately $6 \%(240,000)$ of those pregnancies there will be some kind of glucose intolerance. In about $10 \%$ of these the diagnosis of diabetes will antedate the pregnancy. The remaining $90 \%$ will have gestational diabetes; or glucose intolerance discovered only during pregnancy [1]. Poor maternal glucose control during the first eight weeks of pregnancy, with subsequent hyperglycemia and lipid peroxidation, can have severe implications for the fetus including birth defects [2]. It is well known that, in the USA, congenital anomalies are the leading cause of infant death [3] (Mathews \& MacDorman. Natl Vital Stat Report 2010; 58:1). Likewise, other risks to the newborn from maternal diabetes include shoulder dystocia, respiratory distress syndrome, macrosomia and metabolic derangement, any of which may lead to a costly admission to the neonatal intensive care unit [4]. Similarly, maternal risks of diabetes include increased rates of labor induction, abdominal delivery, infection, hypertension and diabetic ketoacidosis [5]. Finally, women with diabetes also have a life expectancy 12.9 years lower than women without diabetes [6].

If that's the bad news, the good news is that women with diabetes (pre-existing and gestational) can have near normal pregnancies with little increase in morbidity if glucose excursions are well controlled throughout pregnancy [7]. This statement presupposes that women who will develop gestational diabetes can be diagnosed and treated early in pregnancy. Accordingly, if women with known diabetes have preconception counseling and a planned pregnancy, intervention can lead to tight glucose control before gestation and during the crucial period of organogenesis thus reducing birth defects. In addition, if glucose excursions are well controlled throughout pregnancy neonatal complications such as macrosomia/large for gestational age status, shoulder dystocia and respiratory/metabolic complications may be ameliorated [4]. Importantly, tight glucose control before/ during pregnancy may help avoid the metabolic syndrome in children (Figure 1). It has been demonstrated that the metabolic syndrome risk is approximately $50 \%$ when a large for gestational age infant is the product of a pregnancy with maternal gestational diabetes [8].

Traditionally, the screening and diagnosis of gestational diabetes in the United States is a two-step process and is performed at 24 to 28 weeks of gestation. The process begins with a random 50 gram oral glucose load followed by a one hour plasma glucose determination [1]. If the screening result is greater than or equal to $140 \mathrm{mg} / \mathrm{dl}$ the diagnostic test, typically a fasting $100 \mathrm{~g}$ oral glucose tolerance test with plasma glucose levels determined at fasting, one-hour, two-hour, and three-hour intervals, is performed. Two abnormal (elevated) levels will herald the diagnosis of gestational diabetes. To address the issue of early diagnosis, the International Association of Diabetes and Pregnancy Study Group (IADPSG) [9] recommended two paradigm shifts. First, all patients should be screened for hyperglycemia at the first prenatal visit either using a hemoglobin $\mathrm{A}_{1 \mathrm{C}}$ or fasting plasma glucose. If the fasting level is $\geq 92 \mathrm{mg} / \mathrm{dl}, \geq 5.1 \mathrm{mmol} / \mathrm{l} \mathrm{but},<126 \mathrm{mg} /$ $\mathrm{dl}$ is $<7.0 \mathrm{mmol} / \mathrm{l}$ a diagnosis of gestational diabetes is made. This will result in more women being diagnosed with gestational diabetes earlier than the 24-28 week period thus allowing more time to control glucose excursions [9]. Secondly, in those with a normal test result, a
75 gram glucose tolerance test is used for diagnosis using lower plasma thresholds and only one abnormal value being required to diagnose gestational diabetes ( $\geq 92 \mathrm{mg} / \mathrm{ld}$ fasting; $\geq 180 \mathrm{mg} / \mathrm{dl}-1$ hour; $\geq 153$ $\mathrm{mg} / \mathrm{dl}-2$ hour; Table 1); the one-step approach.

The vast majority of obstetricians in the United States have not adopted the IADPSG [6] policy because, to date, there is no consensus that the diagnosis of more women with diabetes $(12.9 \%$ - two-step method versus $37.7 \%$ - one-step method) will result in improved maternal-fetal outcomes $[10,11]$. Such data is just starting to accumulate. Landon et al. [4], has shown that if the fasting blood glucose is greater than $90 \mathrm{mg} / \mathrm{dl}$ and 1-hour greater than $165 \mathrm{mg} / \mathrm{dl}$, there is more neonatal morbidity. If the 1-hour is greater than $150 \mathrm{mg} /$ $\mathrm{dl}$ there is also an increase in large for gestational age infants. Further,

\section{METABOLIC SYNDROME IN CHILDHOOD}

\section{- Metabolic syndrome diagnosed when three of five categories met \\ - Obesity \\ - Hypertension \\ - $\mathrm{CHO}$ intolerance \\ - Low HDL \\ - Hypertriglyceridemia \\ Figure 1: Metabolic syndrome in childhood.}

\begin{tabular}{|c|c|c|c|c|}
\hline $\begin{array}{l}\text { Glucose Diagnostic Levels for } \\
\text { Gestational Diabetes }\end{array}$ & Fasting* $^{*}$ & 1-hour & 2-hour & 3-hour \\
\hline Carpenter/Couston ${ }^{0}$ & 95 & 180 & 155 & 140 \\
\hline National Diabetes Data Group (NDDG) ${ }^{0}$ & 105 & 190 & 165 & 145 \\
\hline $\begin{array}{l}\text { International Association of Diabetes }{ }^{+} \\
\text {And Pregnancy Study Group } \\
\text { (IADPSG_ }\end{array}$ & 92 & 180 & 153 & - \\
\hline
\end{tabular}

${ }^{*} \mathrm{mg} / \mathrm{dl}$,

oTwo step method (50gm oral load - 1 hour glucose) - If $>140 \mathrm{mg} / \mathrm{dl}$, a 3 hour glucose tolerance test is performed

+One step method (75gram oral load followed by 2 hour GTT

Table 1: Diagnostic Criteria for Gestational Diabetes.

*Corresponding author: John C Morrison, University of Mississippi Medical Center, Department of Obstetrics \& Gynecology, 2500 North State Street Jackson, Mississippi 39216, USA, Tel: 601-984-5376; Fax: 601-984-6904; E-mail: jmorrison@umc.edu

Received May 05, 2015; Accepted May 28, 2015; Published June 03, 2015

Citation: Morrison JC, Bofill JA (2015) Gestational Diabetes: A Conundrum for Mother, Baby and Physician. J Diabetes Metab 6: 567. doi:10.4172/2155 6156.1000567

Copyright: @ 2015 Morrison JC, et al. This is an open-access article distributed under the terms of the Creative Commons Attribution License, which permits unrestricted use, distribution, and reproduction in any medium, provided the original author and source are credited. 
Mayo et al. [12] have shown that when the two modes of testing were compared, there was an increase in the diagnosis of gestational diabetes with the one-step 75 gram oral GTT method. However, both testing modalities had increased Cesarean delivery rates as well as increases in large for gestational age infants and composite neonatal morbidity demonstrating that the additional women diagnosed with gestational diabetes were also at an increased risk for adverse outcome. Fong et al. [13] have shown that using a hemoglobin $A_{1 C}$ of greater than $6.5 \%$ (which is currently the standard) at the first prenatal visit is more sensitive than the 1-hour oral glucose load in screening for gestational diabetes. However, when the level of hemoglobin $\mathrm{A}_{1 \mathrm{C}}$ is reduced to a cut point between $5.7 \%$ and $6.4 \%, 27.3 \%$ were diagnosed gestational diabetes compared to $8.7 \%$ if the hemoglobin $\mathrm{A}_{1 \mathrm{C}}$ cut off was $<5.7 \%$. This increase in diagnosis remained after statistical adjustment for maternal age, body mass index, ethnicity and gestational age.

In contrast, it has been pointed out by several national groups and major editorials in major journals in the United States that just because we can make more frequent diagnoses of gestational diabetes, doesn't make it right $[1,11,14-17]$. At present, using Level 1 data, it has not been confirmed that the more frequent diagnosis of gestational diabetes has translated into better maternal, fetal, and neonatal outcomes. There are other problems, as well. In parts of the United States there is a critical shortage of physicians and nurses (in addition to dieticians and diabetes educators). The $18 \%$ increase in cases of gestational diabetes would produce a serious strain on medical manpower [17]. Also, the IADPSG recommendations have been found to be cost effective only when the patients receive additional prenatal monitoring as well as counseling and education in behavior modification [18]. Consideration should also be given to the concern that the new diagnostic criteria may inappropriately designate women with mild degrees of hyperglycemia as having diabetes and this could have significant personal consequences such as unnecessary testing or an altered insurance rating. The additional cases of gestational diabetes could also portend an increase in the obstetrician's medicolegal profile [17]. Therefore, in the United States, it appears that more Level 1 evidence is required as well as evaluation of long-term outcomes in both groups before the new paradigm can be placed into practice [19]. Clearly only time will tell regarding which testing schema will prove best for all concerned.

Why have we not seen an overall change in morbidity and mortality when gestational diabetes is diagnosed? Principally, our problem seems to revolve around the difficulties in achieving "tight" control of glucose excursions in pregnancy. Obviously, blood glucose levels after meals are affected by the triad of diet, exercise and medication. Even in the most stable patient, it is difficult to balance these three factors in order to control glucose during the entirety of the gestation. Optimal glycemic control is shown on Table 2 and is usually evaluated in patients with gestational diabetes by fasting glucose and either preor post-meal testing. For many with gestational diabetes, appropriate glucose control can be achieved effectively by diet alone or with oral hypoglycemic agents such as biguanides (metformin) or sulfonylureas (glyburide) [20]. The best results are usually achieved when a motivated patient has access to frequent telephone contact with a dietician and/or a nurse skilled in diabetes (with the appropriate physician supervision). For women who continue to have difficulty with glucose control, insulin may be substituted for the oral agents when fasting blood glucose is $\geq 100 \mathrm{mg} / \mathrm{dl}$, hemoglobin $\mathrm{A}_{1 \mathrm{C}} \geq 6.0 \%$, or 2-hour post-prandial blood glucose is persistently $\geq 120 \mathrm{mg} / \mathrm{dl}$. An insulin with intermediate duration of such as NPH is usually combined with regular or a rapid acting insulin and both are given in split doses, 2/3 in the AM and 1/3 in the PM to achieve tight glucose control (Table 2).

Post-partum glycemic assessment is also important. It is our policy to check fasting or random plasma glucose 1-3 days after delivery to detect abnormal glucose levels (fasting $\geq 100 \mathrm{mg} / \mathrm{dl}$, random $\geq 140$ $\mathrm{mg} / \mathrm{dl}$ ). Around the time of the first post-partum visit (approximately six weeks) a fasting plasma or 2-hour post-prandial glucose level is performed. If the result is normal then the glycemic status should be assessed every three years with diet and exercise counseling, as required. If there is impaired fasting glucose ( $\geq 100 \mathrm{mg} / \mathrm{dl}$ ) or impaired- glucose tolerance $(\geq 140 \mathrm{mg} / \mathrm{dl}$ ) or both, patients typically receive intensive dietary counseling. If this does not result in excellent glucose control then oral agents can be added. If this results in good control then oral medications are continued with frequent assessment of glycemic status (Figure 2). If oral agents do not result in good postpartum control, the diagnosis of Type 2 diabetes mellitus is made and the patient referred to an internist or endocrinologist for management.

Another unanswered question is who should manage such patients during pregnancy, as achieving tight glucose control is paramount. While trained obstetricians/gynecologists are educated in the management of gestational diabetes, it may be very difficult for the busy clinician to spend the extra time that each of these patients require. These women will commonly have weekly visits and frequent telephone contact. In addition, a host of other professionals such as dieticians, diabetic nurse educators, and skilled sonographers are required to provide optimal care. Any provider should not only be proficient in the management of patients with diabetes but also in women who are also pregnant with

Optimal Glycemic Control ${ }^{1}$

\begin{tabular}{|c|c|}
\hline & Pregnant \\
\hline Fasting & $65-100 * /$ \\
\hline Pre-meal & $60-105$ \\
\hline Post meal & $1 \mathrm{hr}<140$ \\
\hline $2 \mathrm{am}-6 \mathrm{am}$ & $2 \mathrm{hr}<120$ \\
\hline $\mathrm{HbA}_{1 \mathrm{c}}$ & $65-135$ \\
\hline & $<6.0 \%$ \\
\hline
\end{tabular}

${ }^{*} \mathrm{mg} / \mathrm{dl}$

Table 2: Optimal glycemic control for diabetes during pregnancy.

\section{Postpartum Screening for Obstetricians/Gynecologists}

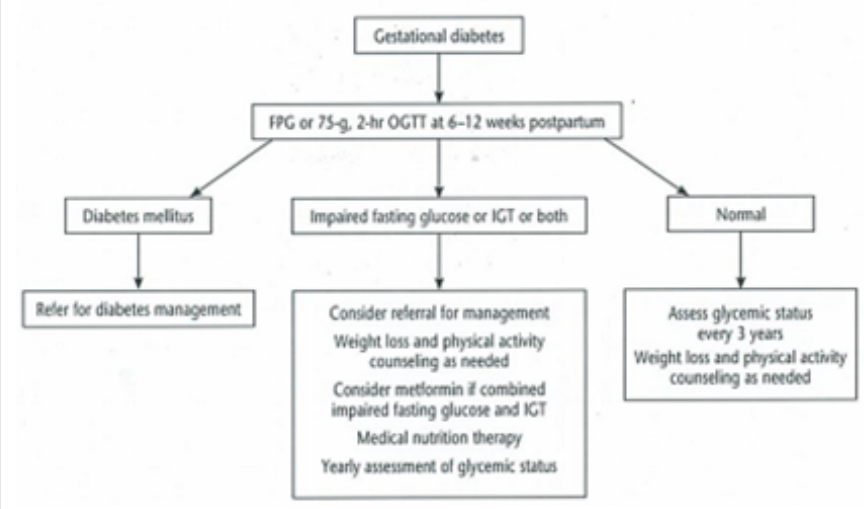

Figure 2: Postpartum glucose assessment for women with gestational diabetes. 
disabilities. To have such resources within a busy practice as well as an obstetrician/gynecologist with the time to manage these patients may be overwhelming. Therefore, many obstetricians/gynecologists will team with an Internal Medicine physician or Endocrinologist who usually have access to diabetic centers (inside or outside of local hospital facilities) to establish cooperative management. Another method would be referral and subsequent co-management with MaternalFetal Medicine specialists. Finally, in complicated cases of gestational diabetes it may be optimal for the Maternal-Fetal Medicine specialist to primarily manage such women. For diabetic patients who live great distances from sub-specialist, telemedicine may be very helpful. It is important to remember that the goal of diagnosis and management of gestational diabetes is a healthy mother and a healthy baby not just during pregnancy and delivery but throughout life. By working together with the patients and physicians as well as other members of the health care team, we can achieve this goal.

\section{References}

1. ACOG Practice Bulletin (2013) Gestational Diabetes Mellitus. Clinica Management Guidelines for Obstetrician-Gynecologists. 137

2. Vaaramaki M, Gissler M, Ritvanen A, Hartikainen AL (2002) Congenital Anomalies and First Life Year Surveillance in Type 1 Diabetic Births. Diabet Med 19: 589-593.

3. Mathews TJ, MacDorman MF (2010) Infant mortality statistics from the 2010 period linked birth/infant death data set. National Vital Stat Report 62.

4. Landon MB, Mele L, Spong CY, Carpenter MW, Ramin SM, et al. (2011) The relationship between maternal glycemia and perinatal outcome. Obstet Gynecol 117: 218-224.

5. Casey BM, Lucas MJ, Mcintire DD, Leveno KJ (1997) Pregnancy outcomes in women with gestational diabetes compared with the general obstetric population. Obstet Gynecol 90: 869-873.

6. Livingston SJ, Levin D, Looker HC, Lindsay RS (2015) Estimated life expectancy in a Scottish cohort with type 1 diabetes, 2008-2010. JAMA 313: 37-44.

7. Langer O, Rodriguez DA, Xenakis EM, McFarland MB, Berkus MD, et al (1994) Intensified versus conventional management of gestational diabetes. Am J Obstet Gynecol 170: 1036-1046.
8. Boney CM, Verma A, Tucker R, Vohr BR (2005) Metabolic Syndrome in Childhood: Association with Birth Weight, Maternal, Obesity, and Gestational Diabetes Mellitus. Pediatrics 115: e290-296.

9. Metzger BE, Gabbe SG, Persson B, Lowe LP, Buchanan TA, et al (2010) International association of diabetes and pregnancy study groups recommendations on the diagnosis and classification of hyperglycemia in pregnancy. International Association of Diabetes and Pregnancy Study Groups Consensus Panel. Diabetes Care 33: 676-682.

10. Agarwal MM, Dhatt GS, Shah SM (2010) Gestational diabetes mellitus: simplifying the international association of diabetes and pregnancy diagnostic algorithm using fasting plasma glucose. Diabetes Care 33: 2018-2020.

11. American College of Obstetrics and Gynecology (2011) Committee Opinion No. 504. Screening and diagnosis of gestational diabetes mellitus. Obstet Gynecol 118: 751-753.

12. Mayo K, Melamed N, Vandenberghe $H$, Berger $H$ (2015) The impact of adoption of the international association of diabetes in pregnancy study group criteria for the screening and diagnosis of gestational diabetes. Am J Obstet Gynecol 212 : 224.e1-9.

13. Fong A, Serra AE, Gabby L, Wing DA, Berkowitz KM (2014) Use of hemoglobin $\mathrm{A} 1 \mathrm{C}$ as an early predictor of gestational diabetes mellitus. Am J Obstet Gyneco 211: 641.e1-7.

14. Current Commentary (2013) National Institutes of Health Consensus Development Conference Statement. Diagnosing Gestational Diabetes Mellitus, March 4-6, 2013. Obstet Gynecol 122: 358-368.

15. Coustan, Donald R (2005) Making the Diagnosis of Gestational Diabetes Mellitus. Clinical Obstetrics and Gynecology 43: 99-105.

16. Langer O, Umans JC, Miodovnik M (2013) Perspectives on the proposed gestational diabetes mellitus diagnostic criteria. Obstet Gynecol 121: 177-182.

17. Reece EA, Moore T (2013) The diagnostic criteria for gestational diabetes: to change or not to change? Am J Obstet Gynecol 184: 255-264.

18. Werner EF, Petker CM, Zuckerwise L, Reel M, Funai EF, et al. (2012) Screening for gestational diabetes mellitus: are the criteria proposed by the International Association of the Diabetes by the International Association of the Diabetes and Pregnancy Study Group cost-effective? Diabetes care 35: 529-535.

19. Saade GR (2013) Expanding the screening for diabetes in pregnancy. Overmedicalization or the right thing to do? Obstet Gynecol 122: 195-197.

20. Hughes RC, Rowant JA (2005) Pregnancy in women with Type 2 diabetes: who takes metformin and what is the outcome? 23: 318-322. 